\title{
Inhalt
}

Einleitung . . . . . . . . . . . . . . . . 13

Michael A. Meyer

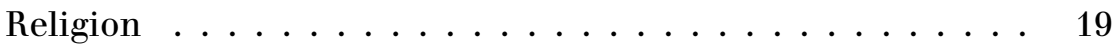

\section{LEBEN UND WIRKEN}

Rabbiner in Oppeln, Düsseldorf und Berlin . . . . . . . . . 23

Oppeln ......................... 23

Rezension zu Der Kalam in der Jüdischen Literatur. Von

Martin Schreiner (26) - Orthodox oder ceremoniös? (31) -

Zur Rabbinerausbildung (35) - Religion des Volkes und

Religion des Individuums (36) - Das Kleine und das

Grosse (40) - Gemeindeleben (43) - Ansprache für einen

Barmitzva (47) - Abschiedspredigt in Oppeln am 1. Oktober

1907 (49) - Aphorismen (55)

Düsseldorf . . . . . . . . . . . . . . . . . . .

Christliche Kultur (59) - Jüdische Kultur (62) - Die Umkehr zum Judentum (63) - »Natürlich" und Aehnliches (69) - Zur Frage der Christusmythe (73) - Unsere Stellung zu den Religionsgesprächen (80) - Englische Frömmigkeit (83) - Wahrheit und Gerechtigkeit (87) - Gesetzesreligion und Religionsgesetz (91) - Das Judentum unter den Religionen (95) Gestern und morgen (103)

Erste Jahre in Berlin

Amtseinführung in Berlin am 27. Dezember 1912 (107) -

Der Stil des Lebens (108) - Die Schöpfung des Mitmenschen (112) 
Feldrabbiner im 1. Weltkrieg . . . . . . . . . . . . . . . . . 119

Das Drama der Geschichte (120) - Du sollst! (124) - Draussen und Drinnen (128) - Die Kraft der Wenigen (130) Berichte des Feldgeistlichen Rabbiner Dr. Leo Baeck an den Vorstand der jüdischen Gemeinde (133) - Brief an Martin Buber (142)

Die Weimarer Jahre . . . . . . . . . . . . . . . . . . . . 143

"Die Lehren des Judentums" . . . . . . . . . . . . . . . . . . 143

Sittlichkeit als Grundforderung des Judentums (144) - Wille zum Leben (146) - Wahrhaftigkeit (148) - Der soziale Charakter des Judentums (151) - Der ewige Friede (154) Inbegriff von Sittlichkeit, Liebe, Gerechtigkeit und Heiligkeit (156) - Die Auseinandersetzung mit dem entstehenden Christentum (157) - Abweichungen der christlichen Religionen vom Judentum in den Grundgedanken. Einleitung (162) - Jüdische Anerkennung individueller Glaubensauffassung (165)

Vermischte Schriften . . . . . . . . . . . . . . . . . . 170

Zedakah (172) - Entwickelung und Wiedergeburt (173) Die Ehe als Geheimnis und Gebot (179) - Okkultismus und Religion (185) - Vorwort zu Aimé Pallière. (188) - Das unbekannte Heiligtum (188) - Die jüdischen Gemeinden (193) Mensch und Boden (201) - Gedanken und Soziologie des Großstadtjuden (201)

Vorahnungen ..................... 204

Brief an Caesar Seligmann (204) - ... alles wahre Ideale erstorben (206) - Vorwort zu Friedhofsschändungen in Deutschland (207)

Im nationalsozialistischen Berlin . . . . . . . . . . . . 209

Politisches ....................... 209

Das deutsche Judentum und die Erneuerung Deutschlands (210) - Trauer um Hindenburg (211) - Ansprache auf der Trauergedenkfeier für Reichspräsident Hindenburg (211) - An den Herrn Reichskanzler Adolf Hitler (213)

Judentum . . . . . . . . . . . . . . . . . . . 215

Das Judentum in der Gegenwart (216) - Umwälzung und Umwandlung (220) - Religionen (223) - Der jüdische Geist (224) - Chukkat haggoj (226) - Das jüdische 
Jahr (227) - Der jüdische Mensch (232) - Die Existenz des Juden (245) - Die Gestalt des deutschen Judentums (253) Schöpfungsordnungen (259) - Die Wüste (262) - Zeiten und Tage (264)

Kunst und Kultur . . . . . . . . . . . . . . . . . . . 267

Für den Kulturbund Deutscher Juden (268) - Kunst und Leben (268) - Sprache (270) - Bildungsenge? (271) - Zum Sportereignis des Jahres im Sportbund des Reichsbundes jüdischer Frontsoldaten (273) - Zum Geleit eines Katalogs (273) - Europa (274) - Die Ferne (280)

Gemeinde und gemeinsame Pflicht . . . . . . . . . . . . . . 283

An die deutschen Juden! (284) - Religiöse Erneuerung (286) - Unsere Gemeinde (287) - Erklärung der Reichsvertretung (288) - Wie gestalte ich den Schabbat? (289) - Saar-Kundgebung der Reichsvertretung (290) Erziehen und Helfen (291) - Ansprache zur Eröffnung der Jüdischen Winterhilfe (292) - Wahrheit und Gemeinsamkeit (293) - Die jüdische Sozialarbeit umspannt die Welt! (294) - Pflicht hört nie auf (295) - Hineni - hier bin ich! (296)

Ermutigung . . . . . . . . . . . . . . . .

Recht und Pflicht! (299) - Tag des Mutes (300) - Die Freien und die Unfreien (301) - Tage und Leben (302) - Zurückhaltung (303) - Was sollen wir denn tun ... (304) - Zukunft des Judentums (305) - Festrede des Großpräsidenten zum 50. Stiftungsfest der Lessing-Loge des Bne Briss (306) "Tröstet, tröstet mein Volk " (311) - Ansprache zum Kol Nidre des Versöhnungstages 6. Oktober 1935 (312) - Die Reichsvertretung an die Juden in Deutschland (313)

An und für Einzelne . . . . . . . . . . . . . . . . . .

Briefe an Alfred M. Cohen in Cincinnati (316) - Leo Baeck an Dr. Rubinow in Cincinnati (320) - Brief an Dr. Morgenstern in Cincinnati (321) - Brief an Dr. Samuel Schulman in New York (322) - Zu Martin Bubers 60. Geburtstag (323) - Brief an Lily H. Montagu in London (323) - Brief an Chief Rabbi J. H. Hertz in London (325) - Leo Baeck an Max Grünewald (326) - Briefe an Manfred Swarsensky in London (327) - Brief an Immanuel Löw in Szeged, Ungarn (330) - Brief an Hans Hirsch in Ithaca, New York (331) Referenz für Wolfgang Hamburger (332) - Brief an Rudolfo 
Löb in Buenos Aires (332) - Brief an Hans Schäffer in Schweden (333) - Brief an Ilse Blumenthal-Weiss in Holland (334)

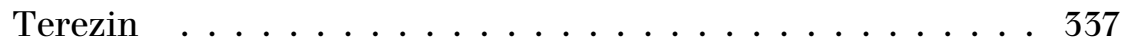

Postkarte an Immanuel Löw in Szeged, Ungarn (339) - Postkarte an Dr. Rant (339) - Hermann Strauss zum Geburtstag (340) - Vorträge in Theresienstadt (341) - Geschichtsschreibung (342) - Brief an Else Nathan in Tel Aviv (358) Briefe in Auszügen (359) - Vision und Geduld (361) - Briefe an H. G. Adler in London (365) - Geleitwort zu H. G. Adlers Theresienstadt (366)

Nach der Shoa . . . . . . . . . . . . . . . . . 369

Das neue Deutschland und seine Vergangenheit . . . . . . . . 369

Ein Gespräch mit Leo Baeck im Aufbau (370) - Eine Botschaft von Leo Baeck (371) - Brief an Constantin Cramer von Laue in Hildesheim (373) - Referenz für Hans Walz (375) Brief an Hans Walz (376) - Juden und Deutsche (376) Antwort an Bonn (377) - Auszug aus einem Interview in Kopenhagen (379)

Das Erbe des deutschen Judentums . . . . . . . . . . . . . . . 380

Brief an Salo Baron in New York (381) - Brief an Hermann Muller in New York (382) - Brief an Georg Landauer in Jerusalem (383) - Brief an die JRSO (385) - Brief an Monroe Goldwater in New York (386) - »Die Idee bleibt« (387) - Brief an Henrique Lemle in Rio de Janeiro (390) - Die deutschen Juden (390) - Erbe und Aufgabe (392) - Bewährung des Deutschen Judentums (394)

Die neue jüdische Gemeinde in Deutschland . . . . . . . . . . . . 399

Brief an Dr. Farbstein (399) - Brief an Nathan Peter Levinson in Berlin (401) - Brief an Robert Raphael Geis in Karlsruhe (403) - Brief an die Arbeitstagung jüdischer Juristen in Düsseldorf (405)

Aufsätze ....................... 406

Vom Gewissen (407) - Das Schema (409) - Pessach (414) Individuum und Gemeinschaft (415) - Staat und Kultur (417) - Die vier Stationen des Lebens (421) - Leben und Kunst (436) - Gerechtigkeit (440) - Menschlichkeit (444) Frieden (447) - Voraussetzungen der Toleranz (453) 


\section{ÜBERGREIFENDE THEMEN}

Zionismus und Israel $\ldots \ldots \ldots$. . . . . . . . . . . 459

Brief an Emil Bernhard-Cohn in Berlin (461) - Der Aufbau Palästinas und das deutsche Judentum (461) - Das Palästinawerk (464) - Stellung des religiös-liberalen Judentums zum Zionismus (468) - "Agency«-Kundgebung (469) Unsere Hoffnung (471) - Über das jüdische Palästina Ein Interview (472) - Brief an Werner David Senator in Jerusalem (475) - Judentum und Zionismus (477) - Brief an J. L. Magnes in Jerusalem (480) - Kooperation in Palästina Ein Appell (480) - Religiöse Erziehung in Palästina (482) Das Überleben des Geistes (485) - Brief an Hans Paeschke in München (487) - Gutachten vom Oktober 1951 (488) - Brief an David Werner Senator in Jerusalem (491) - »... und über die Staaten wird der Spruch getan“ (491)

Progressives Judentum

Brief an Lily H. Montagu in London (497) - Die Bedeutung der Londoner Tagung (497) - Die Botschaft des Judentums an das Individuum (499) - Fragen des jüdischen Ehegesetzes (504) - Das Zusammensitzen von Männern und Frauen in der Synagoge Prinzregentenstraße in Berlin (507) - Rede auf der Tagung der World Union for Progressive Judaism in London, 1930 (511) - Brief an Lily H. Montagu in London (515) - »Ideen kämpfen heute miteinander" (515) - Die Zukunft des Liberalen Judentums (517) Die Prinzipien der Progressiven Bewegung des Judentums (520) - Die Mission des Judentums (525)

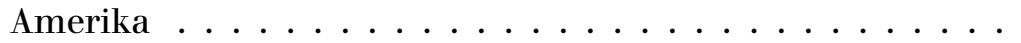

Amerika (532) - Briefe von Baecks Amerika-Reise 1925 an Natalie Baeck in Berlin (536) - Rede vor einer Bne Briss Loge (539) - Gebet im Repräsentantenhaus am 12. Februar 1948 (549) - Ein Meilenstein in dem Leben eines Volkes (550) - Ansprache zum Gründungstag des Hebrew Union College in Cincinnati (550) 


\section{KORRESPONDENZEN}

Micha Josef Berdyczewski . . . . . . . . . . . . . . . . . 559

Ismar Elbogen . . . . . . . . . . . . . . . . . . . . . 563

Franz Rosenzweig . . . . . . . . . . . . . . . 576

Hermann Graf Keyserling . . . . . . . . . . . . . . . . 586

Paul Graf Thun-Hohenstein . . . . . . . . . . . . . . . 592

Hans-Hasso von Veltheim-Ostrau . . . . . . . . . . . . . . . 597

Chaim Weizmann . . . . . . . . . . . . . . . . . . . . . . 622

Ludwig Meidner . . . . . . . . . . . . . . . . . . . . . . 628

Albert Einstein . . . . . . . . . . . . . . . . . 633

Ernst Ludwig Ehrlich ～. . . . . . . . . . . . . . . . 636

Gertrud Luckner . . . . . . . . . . . . . . . . . . . . . . . 6473

Gershom Scholem . . . . . . . . . . . . . . . . . . . . 649

Robert Raphael Geis . . . . . . . . . . . . . . . . . 654

Ernst G. Lowenthal . . . . . . . . . . . . . . . . . . . . . . 661

Rudolf Jaser . . . . . . . . . . . . . . . . . . . . 667

Theodor Heuss ． . . . . . . . . . . . . . . . . . 683

Das Ende einer Epoche . . . . . . . . . . . . . . 695

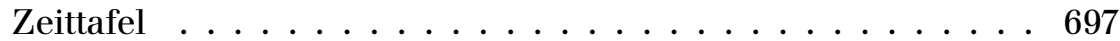

Namenregister . . . . . . . . . . . . . . . 699 